\title{
Experiences of using mobile technologies and virtual field tours in Physical Geography: implications for hydrology education
}

\author{
D. G. Kingston ${ }^{1,2}$, W. J. Eastwood ${ }^{1}$, P. I. Jones ${ }^{1}$, R. Johnson ${ }^{1}$, S. Marshall ${ }^{3}$, and D. M. Hannah ${ }^{1}$ \\ ${ }^{1}$ School of Geography, Earth and Environmental Sciences, University of Birmingham, Edgbaston, Birmingham, B15 2TT, UK \\ ${ }^{2}$ Department of Geography, University of Otago, P.O. Box 56, Dunedin, New Zealand \\ ${ }^{3}$ Marlin Productions Ltd., Birmingham, UK
}

Correspondence to: D. G. Kingston (daniel.kingston@geography.otago.ac.nz)

Received: 28 November 2011 - Published in Hydrol. Earth Syst. Sci. Discuss.: 14 December 2011

Revised: 30 March 2012 - Accepted: 14 April 2012 - Published: 3 May 2012

\begin{abstract}
Education in hydrology is changing rapidly due to diversification of students, emergent major scientific and practical challenges that our discipline must engage with, shifting pedagogic ideas and higher education environments, the need for students to develop new discipline specific and transferrable skills, and the advent of innovative technologies for learning and teaching. This paper focuses on new technologies in the context of learning and teaching in Physical Geography and reflects on the implications of our experiences for education in hydrology. We evaluate the experience of designing and trialling novel mobile technology-based field exercises and a virtual field tour for a Year 1 undergraduate Physical Geography module at a UK university. The new exercises are based on using and obtaining spatial data, operation of meteorological equipment (explained using an interactive DVD), and include introductions to global positioning systems (GPS) and geographical information systems (GIS). The technology and exercises were well received in a pilot study and subsequent rolling-out to the full student cohort ( $\sim 150$ students). A statistically significant improvement in marks was observed following the redesign. Although the students enjoyed using mobile technology, the increased interactivity and opportunity for peer learning were considered to be the primary benefits by students. This is reinforced further by student preference for the new interactive virtual field tour over the previous "show-and-tell" field exercise. Despite the new exercises having many advantages, exercise development was not trivial due to the high start-up costs, the need for provision of sufficient technical support and the relative difficulty of making year-to-year changes (to the virtual field tour in particular). Our experiences are highly relevant to the
\end{abstract}

implementation of novel learning and teaching technologies in hydrology education.

\section{Introduction}

Education in hydrology is changing rapidly as a result of a number of factors. These include, but are not limited to, a diversifying student population, new and emerging major scientific and practical challenges that our discipline must engage with (e.g. climate change, prediction in ungauged basins, water security, hydrohazards), shifting pedagogic ideas and higher education environments, the need for students to develop new discipline specific and transferrable skill sets, and the advent of innovative technologies for learning and teaching (Nash et al., 1990; Wagener et al., 2007). This paper focuses on new technologies in the context of learning and teaching across the discipline of Physical Geography and reflects on the implications of our experiences for the future of education in hydrology.

Mobile technology can be defined as portable (handheld) computers, typically with global positioning system (GPS) capability (e.g. personal data assistants (PDAs), smartphones). The possible benefits for learning from the use of mobile technologies are thought to be especially pertinent for field-based subjects such as hydrology in that they permit greater locational flexibility in terms of where learning takes place (Siau and Nah, 2006; Walton et al., 2005). In particular, the possibility for situated and context-aware learning, such as through the use of GPS, has the potential to provide a key learning tool. This is because of the importance of field-based 
learning for facilitating "active learning" (i.e. learning by doing), and as such the potential to integrate theories, concepts and skills in a practical environment (Kent et al., 1997; Fuller et al., 2000; Boyle et al., 2003).

Despite the many educational benefits of field-based learning, fieldwork in itself is not intrinsically linked to effective learning (Lonergan and Andreson, 1988). Furthermore, the relatively high expense of providing field experience is resulting in increasing demands for accountability with respect to the effectiveness of fieldwork (McMorrow, 2005). Aided by advances in technology, the concept of virtual field trips (VFTs) has become increasingly prevalent over recent years as a means to enhance the effectiveness of time spent outside of the classroom (e.g. McMorrow, 2005; Hirsch and Lloyd, 2005). This is because VFTs can be used to provide essential background information that may otherwise have to be delivered in the field (Stainfield et al., 2000). Similarly, learning tasks embedded in VFTs can be used for post-fieldwork revision, assessment or further study (e.g. Hirsch and Lloyd, 2005). Finally, VFTs can provide opportunity for some sort of "field" experience where this would not otherwise be possible, for example due to large student numbers, financial constraints, logistics, or distance from intended field site (Poland et al., 2003; Turney et al., 2004).

This paper evaluates the redesign of a fieldwork-based geographic skills module taught at first year undergraduate level in the UK. This revamp was facilitated by the introduction of mobile technology and a virtual field tour as teaching aides, a combination we understand to be novel. Although primarily concerned with field mapping and climatology, there are strong parallels that can be drawn in terms of the teaching requirements across the discipline of Physical Geography. As such, the mobile technology-based field exercises, virtual field tour, associated pilot-tests and focus group response presented herein provide an important opportunity to investigate and evaluate the effectiveness of these two learning tools across the spectrum of undergraduate Physical Geography subjects (including hydrology). In the context of this special issue, we reflect on the implications of our experiences for education in hydrology.

\section{Background and rationale for changes}

The Physical Environment of Birmingham is a compulsory Year 1 module for BSc and BA Geography students at the University of Birmingham, UK. This module is a cornerstone of the first year Geography programme, and comprises an introduction to basic geographical skills in local field environments using the city of Birmingham as an urban, open-air laboratory. The module includes linked projects on mapping techniques and urban climatology. The original, pre-revamp mapping component was based around paper maps and did not train students in modern computer mapping techniques such as geographical information systems (GIS). The use of mobile technology offers the potential to develop these modern mapping skills and then apply them to real world applications in the urban climatology project. This approach develops student understanding of pertinent theoretical geographical concepts, rather than simply being a case of introducing technology for technology's sake.

The climatology project required collection of in-situ field data for mapping and assessment of the thermal characteristics of an area of southwest Birmingham and an analysis of diurnal weather variation. This was preceded by a tour of the University weather station, which comprised an explanation of the operation and role of the various weather-recording instruments included on a standard UK Meteorological Office Surface Climate Station. As climate drives the water cycle and such weather stations record hydrological variables (e.g. precipitation), this element of the project is of direct relevance to hydrology education. Due to the relatively large numbers of students taking the module (typically 150-200), it had become impractical to take all of the students to the weather station at once. Therefore, students were split into groups of 20-25, with seven tours being re-taught by staff over one afternoon. Clearly, this re-teaching takes up a relatively large amount of staff time. Furthermore, due to module scheduling, the tour occurs in January when day length is relatively short. This timing results in the last group of students visiting the weather station near dusk, which combined with the occasional occurrence of inclement weather, means that this exercise is not always popular (with either students or staff). Although the students were asked questions on the type and operation of instruments in the module assessment, the tour is essentially an observational showand-tell exercise.

\section{New learning and teaching innovations}

Whilst still providing a basic introduction to mapping (including co-ordinate systems, projections, grids and datums), a new practical mapping exercise was produced based on sources of spatial data, together with the concept of accuracy and precision of spatial data. Particular emphasis was given to the use of GPS. As such, the new exercise aims to familiarise students with important basic skills and concepts relevant for geographical analyses (such as of hydrological processes). The exercise itself involves collecting spatial data (in the form of track-logs and waypoints) using GPS-enabled PDAs for various areas of the University campus. This information was subsequently uploaded to a PC and plotted on digital UK Ordnance Survey maps (using the ArcGIS software) and Google Earth images (Fig. 1). The exercise is assessed though a critical discussion of the differences between the collected GPS data, the Ordnance Survey map and Google Earth images.

The air temperature mapping component was redesigned to incorporate the use of GPS and GIS and progressed 


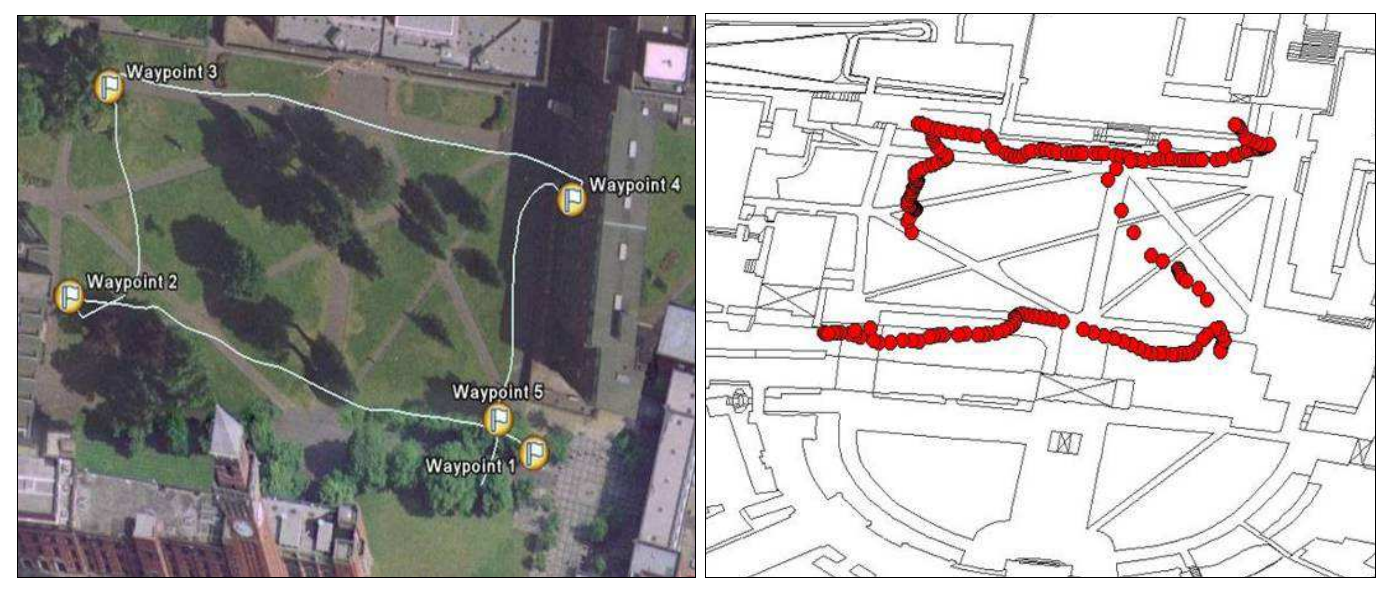

Fig. 1. Sample output of GPS track-logs for the University of Birmingham campus, from Google Earth (left), and ArcMap (right).

from the new mapping project through its practical application of skills. The new exercise comprised use of a GPSsynchronised GIS (using ArcPad software) on the PDAs to record and map temperature readings across a predefined area. These data were transferred to the more powerful desktop-based ArcGIS software to create a temperature surface (using spatial interpolation) to overlay with a map of the local area. A discussion of the reasons for the recorded variation in urban air temperature formed the assessment for this exercise.

To overcome the aforementioned issues with the weather station field visit, a DVD-based interactive virtual weather station "field tour" was produced (Fig. 2). The DVD is presented by the same staff who gave the original show-and-tell tour, and the content is very similar. The total running length of the DVD is approximately $40 \mathrm{~min}$, and consists of a series of short (2-3 min) video sequences explaining the role and operation of various instruments. Each sequence is followed by a set of multiple choice questions, which must be answered correctly before the next sequence can be viewed (Fig. 2b). This means that whilst the DVD-based virtual field tour is still essentially a show-and-tell activity, interactivity on an individual level is forced by the need to answer formative questions. Furthermore, the division of the DVD into short sections provides opportunity for reflection and repeat viewing of the explanation of the weather station operation.

\section{Evaluation}

To facilitate a comparative analysis of the old and new exercises, we needed students to complete both the old and new exercises for the module. As such, at the end of the 2006/2007 academic year (the last year to run the old exercises) we asked for volunteers from the current student cohort to trial the new exercises. We had nine respondents, all of whom were selected to take part in the pilot study. The volunteers were given a week to complete the new exercises (using GPS-enabled PDAs and virtual field tour weather station DVD). They completed a short questionnaire about the exercises, after which a focus group meeting (convened and facilitated by an independent associate staff member) was held to discuss further their opinions.

The feedback from the pilot study questionnaires was very positive (Table 1), particularly for the question of whether useful skills had been gained, and whether the new exercises represented an improvement over the previous versions. The focus group discussion largely confirmed the results of the questionnaire (i.e. students found the new exercises to be more educationally valuable and enjoyable than the old module design). This was stated as being due, in part, to the more active nature of the new tasks (i.e. the incorporation of fieldwork in the mapping project, the need to answer questions within the DVD). The use of PDAs was generally considered to be enjoyable, fun and exciting, while the opportunity to learn about using GIS and GPS was a definite attraction for all. The students particularly enjoyed the flexibility of being able to interact with the DVD at a time of their own choosing, as well as being able to watch it more than once. Given the choice, all students said they would choose to take the redesigned module.

The issue of using relatively sophisticated forms of technology was not found to be a barrier to learning, even by students that considered themselves to be technophobes, with the difficulty of the exercises considered about right. Although the instructions were thought to be as clear and straightforward as possible, some complaints were made about the PDAs being a little awkward to use, due to their small screens, fonts and buttons (reflected in the relatively low questionnaire score for ease of use of PDA). The need for sufficient (timetabled) technical support with respect to both the PDAs and the GIS software was identified, which was subsequently provided as the revised module came into 
a

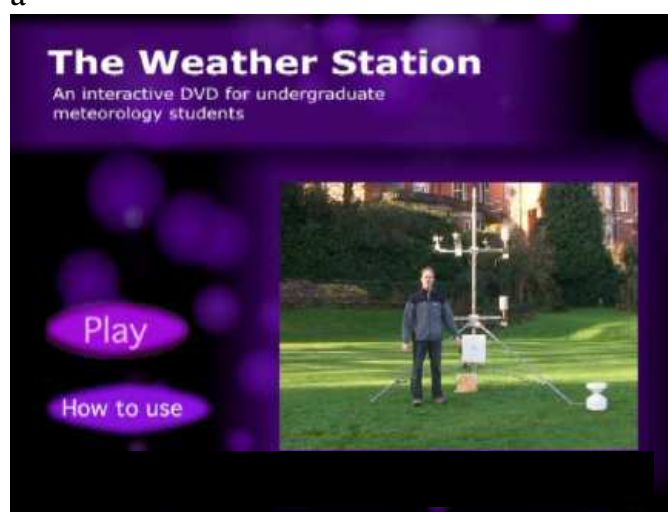

b

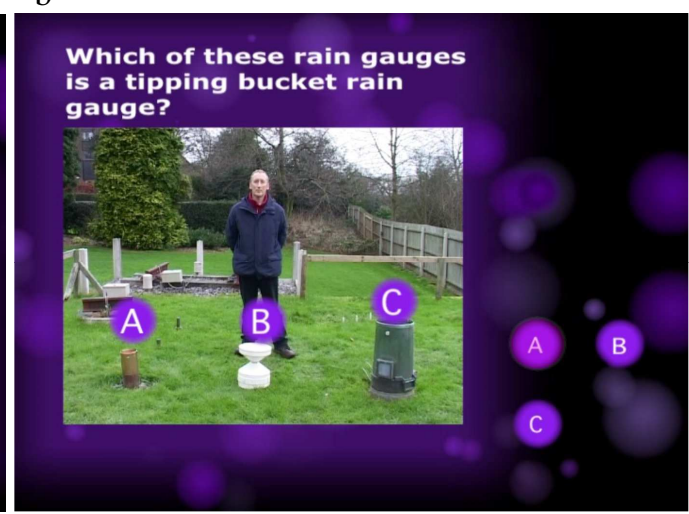

Fig. 2. (a) Start screen for the interactive DVD, (b) example formative multiple choice question from the DVD.

Table 1. Responses to questions from the nine focus group participants. Questions $1-5,7,9-12$ were answered on a likert scale, with 1 indicating a difficult/negative response and 5 easy/positive response. The score for questions 6,8 and 13 refers to the number of participants (out of 9) who agreed with the question.

\begin{tabular}{lll}
\hline Exercise & Question & $\begin{array}{l}\text { Mean } \\
\text { response }\end{array}$ \\
\hline UK Ordnance Survey vs. & 1. Ease of use of PDA? & 3.3 \\
Google Earth mapping & 2. Clarity of instructions? & 4.6 \\
& 3. Difficulty of exercises? & 3.4 \\
& 4. Enjoyment of exercises? & 3.9 \\
& 5. Useful skills gained? & 4 \\
& 6. GPS exercise an improvement (compared to & 8 \\
& $\quad$ previous mapping exercise)? & \\
& 7. GPS exercise: overall rating & 4.2 \\
Temperature mapping & 8. Temperature mapping exercise an & 8 \\
& $\quad$ improvement (compared to previous version)? & \\
& 9. Temperature mapping exercise: & 4.1 \\
& $\quad$ overall rating? & \\
Weather station virtual & 10. Explanation of operation of weather station? & 4.4 \\
& 11. Difficulty of DVD questions? & 3.4 \\
& 12. Confidence in taking measurements? & 3.8 \\
& 13. Prefer original visit? & 1 \\
& 14. Replace visit with DVD? & 3 \\
& 15. Use combination of both? & 5 \\
\hline
\end{tabular}

operation, along with some very basic instructions and FAQ sheet. Although the PDAs were considered to be a significant attraction of the new exercises, there was some nervousness about having to take care of them, especially in a situation of group responsibility.

Despite the high rating for the improved clarity of explanation of the operation of the weather station in the DVD compared to the field trip, and subsequent increased confidence in taking readings from the instruments, most students initially did not want to remove the existing real field visit to the weather station from the module. However, once reassured that there would still be a member of staff on hand when they actually took their first set of project measurements from the weather station, all were happy to have the existing tour replaced by the interactive DVD.

The module has now run in its new form for four years. The cohort mean mark has been higher consistently for the redesigned module (Fig. 3), with a mean of $60.0 \%$ for the three years preceding redesign versus $63.8 \%$ for the following three years. A two-sample t-test shows that the difference in marks between the two three year periods is statistically significant at $p=0.05$. Additionally, there was a much greater proportion of first-class grades (i.e. a mark $\geq 70 \%$, which is the top degree classification category in the UK) compared with the old module (Fig. 3). No first class grades were obtained in the three years prior to the redesign, whereas 


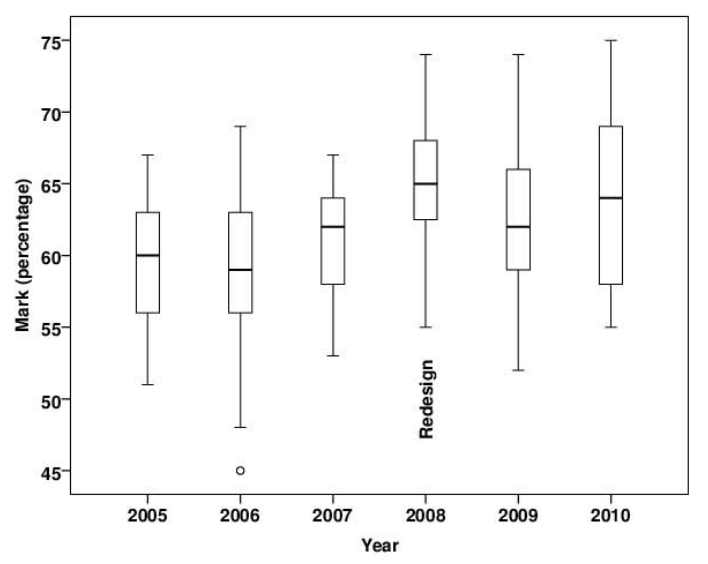

Fig. 3. Pre- and post-redesign marks for the module (median mark indicated by horizontal line, inter-quartile range indicated by box).

between $13-15 \%$ of the class achieved a first class grade in each year following the redesign. Feedback from module development questionnaires confirms findings from the original focus group, with satisfaction scores for the practical classes increasing from a mean of 3.0 to 4.0 (on a 15 Likert scale) between the three years pre- and post-redesign (Fig. 4). A two-sample t-test shows that the difference in marks between the two three year periods is statistically significant at $p=0.05$. Overall satisfaction with the module showed a more modest (and not statistically significant) increase, from 3.6 to 3.7 (on a 1-5 Likert scale; Fig. 4). Written feedback from module development questionnaires following the redesign has noted the DVD and opportunity to use the PDAs frequently as positive elements of the module. Overall, the response has been very good, with comments including "the practicals allow better understanding of topics" and "for someone not "into" physical geog. it was a very interesting course :)".

\section{Discussion and implications for hydrology education}

This paper focuses on mapping and climatology applications but the mobile technologies and virtual fieldwork experiences have direct implications for hydrology education and Physical Geography learning and teaching more widely. The increased interactivity, use of technology, and opportunity for learning by doing provided by the new exercises are considered key causes of the positive student feedback and improved marks achieved by the students (Stainfield et al., 2000). Although the appeal of using the PDAs was undoubtedly high for the students, as with the interactive DVD, it is the enhanced interactivity and opportunity for "learning by doing" that are considered to be the driving forces behind the enthusiasm and success of the students. This emphasises the imperative that it is the nature of the learning exercise, rather than the technology used, that is of most importance when
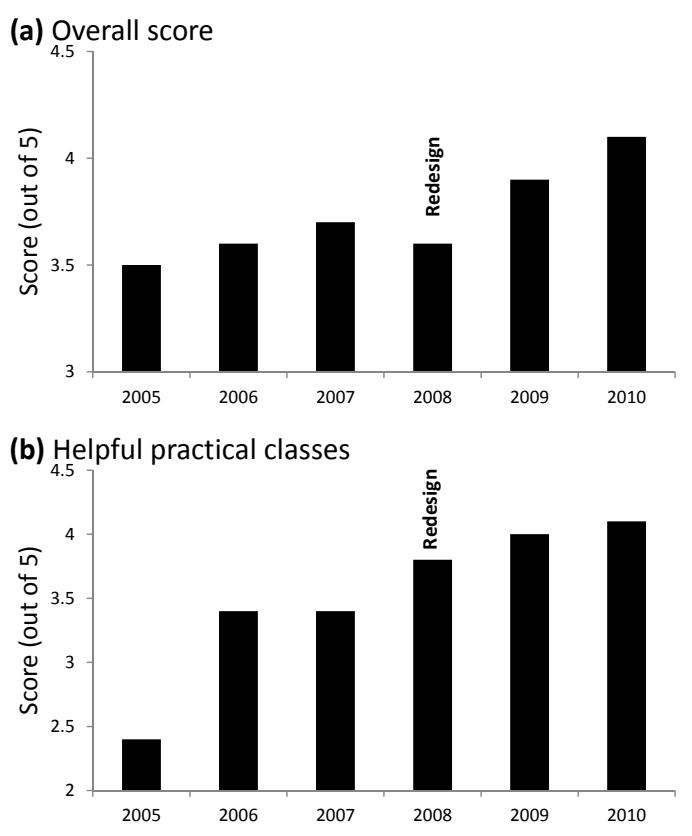

Fig. 4. Pre- and post-innovation cohort mean student feedback (a) overall scores and (b) scores for how helpful practical classes were.

considering the role of technology in education (Fletcher et al., 2007; Pathirana et al., 2012).

From a lecturer's perspective, the interactive DVD is advantageous in that it avoids déjà-vu style repeat teaching (and hydrologists getting wet!) and has represented a significant time-saving now that the module has run for a number of years. However, the front-loading of staff time in terms of designing the exercises (particularly filming and editing the DVD) should not be underestimated, together with technical issues associated with these tasks (Popescu et al., 2012; Rusca et al., 2012; Turney et al., 2004; Smith et al., 2002). The difficulty of making slight year-on-year adjustments to the content of the DVD (in comparison to actual field-based teaching) should also be noted (Mackenzie et al., 2003).

The experience of running this redesigned module provides insight into student perception of virtual versus actual field exercises, although caution is required before any general conclusions can be drawn from this small sample. The strength of feeling expressed in favour of the DVD appears somewhat surprising (especially in light of previous findings - e.g. Spicer and Stratford, 2001); but this may be because the old field exercise was not a particularly good example of "hands-on" fieldwork; it was primarily an observational visit with little interactivity (beyond rhetorical questions and answers) or opportunity for learning by doing. Therefore, it is likely that the increase in interactivity, rather than the transfer to virtual environment, was the key factor in terms of the enthusiasm for the DVD. It is also important to note that the 
students were still required to use the weather station; the virtual field tour is being used to effectively deliver important background information and training in preparation for students going into the field to make their own meteorological observations.

The weather station DVD is amenable to distance learning and also possible distribution to hydrologists in less developed countries to aid in knowledge exchange. The concept of developing an interactive virtual introduction to the principles and operations of field-based equipment could be applied also to other hydrological observations (e.g. discharge or water quality). The DVD offers potential for retraining and lifelong learning to update skills as well as providing a vehicle to enthuse interested laypersons in environmental observation (to discuss the availability of the DVD, please contact David Hannah, University of Birmingham, at d.m.hannah@bham.ac.uk).

The skills gained from using the GPS-enabled PDAs for field mapping are directly applicable to other hydrology field exercises (for example, mapping precipitation, soil moisture or river networks). Competence with such modern technology is an important transferrable skill needed by hydrologists to be effective in a changing and increasing spatially and temporally complex world. Skills with such technology are highly likely to improve the employability of graduates.

In terms of the wider-scale significance of these findings for hydrology, it can be concluded that where virtual fieldwork and mobile technologies have the potential to increase interactivity of the educational experience, they should be welcomed. However, extreme caution is needed before the decision can be made to deprive students of actual field experience. There remains significant value in making first-hand observation related to hydrological and other phenomena because this is vitally important in understanding the complexity of environmental systems and how theoretical knowledge can be applied in a real world context.

Acknowledgements. This work was funded by a Learning Enhancement Project grant from the University of Birmingham Learning Development Unit (LDU). We also thank Bob Hunter of the LDU for helpful advice on the development of this project and Becky Morris for convening and facilitating the focus group meetings.

Edited by: J. Seibert

\section{References}

Boyle, B., Conchie, S., Maguire, S., Martin, A., Milsom, C., Nash, R., Rawlinson, S., Turner, A., and Wurthmann, S.: Fieldwork is Good? The student experience of field courses, Planet, 5, 48-51, 2003.

Fletcher, S., France, D., Moore, K., and Robinson, G.: Practitioner perspectives on the use of technology in fieldwork teaching, J. Geogr. Higher Educ., 31, 319-330, 2007.
Fuller, I., Rawlinson, S., and Bevan, R.: Evaluation of Student Learning Experiences in Physical Geography Fieldwork: paddling or pedagogy? J. Geogr. Higher Educ., 24, 199-215, 2000.

Hirsch, P. and Lloyd, K.: Real and Virtual Experiential Learning on the Mekong: Field Schools, e-Sims and Cultural Challenge, J. Geogr. Higher Educ., 29, 321-337, 2005.

Kent, M., Gilbertson, D. D., and Hunt, C. O.: Fieldwork in geography teaching: a critical review of the literature and approaches, J. Geogr. Higher Educ., 21, 313-332, 1997.

Lonergan, N. and Andreson, L. W.: Field-based education: some theoretical considerations, Higher Education Research and Development, 7, 63-77, 1988.

Mackenzie, D. M., Hudson, N. F. C., Watson, A. P., Gale, J. F. W., Jones, P. F., Regan, P. F., Wilkins, H., and Johnson, T.: The use of C\&IT to support fieldwork teaching and assessment at the University of Derby, Planet, 5, 11-14, 2003.

McMorrow, J.: Using a Web-based Resource to Prepare Students for Fieldwork: Evaluating the Dark Peak Virtual Tour, J. Geogr. Higher Educ., 29, 223-240, 2005.

Nash, J. E., Eagleson, P. S., Philip, J. R., and van der Molen, W. H.: The education of hydrologists, Hydrolog. Sci. J., 35, 12-23, 1990.

Pathirana, A., Gersonius, B., and Radhakrishnan, M.: Web 2.0 collaboration tools to support student research in hydrology an opinion, Hydrol. Earth Syst. Sci. Discuss., 9, 2541-2567, doi:10.5194/hessd-9-2541-2012, 2012.

Poland, R., Baggott la Velle, L., and Nichol, J.: The Virtual Field Station (VFS): using a virtual reality environment for ecological fieldwork in A-Level biological studies - Case Study 3, Brit. J. Educ. Technol., 34, 215-231, 2003.

Popescu, I., Jonoski, A., and Bhattacharya, B.: Experiences from online and classroom education in hydroinformatics, Hydrol. Earth Syst. Sci. Discuss., 9, 1311-1333, doi:10.5194/hessd-91311-2012, 2012.

Rusca, M., Heun, J., and Schwartz, K.: Water management simulation games and the construction of knowledge, Hydrol. Earth Syst. Sci. Discuss., 9, 3063-3085, doi:10.5194/hessd-9-30632012, 2012.

Siau, K. and Nah, F. F. H.: Mobile technology in education, IEEE T. Educ., 49, 181-182, 2006.

Smith, M., Hudson, N., Watson, A., Mackenzie, D., and Gale, J.: A CD-based courseware package for the teaching and consolidating of geological field skills, Planet, 4, 10-12, 2002.

Spicer, J. I. and Stratford, J.: Student perceptions of a virtual field trip to replace a real field trip, J. Comput. Assist. Lear., 17, 345354, 2001.

Stainfield, J., Fisher, P., Ford, B., and Solem, M.: International Virtual Field Trips: a new direction?, J. Geogr. Higher Educ., 24, 255-262, 2000.

Turney, C., Robinson, D., Lee, M., and Soutar, A.: Bringing the mountain to the student: developing a fully integrated online volcano module, Planet, 12, 12-15, 2004.

Wagener, T., Weiler, M., McGlynn, B., Marshall, L., McHale, M., Meixner, T., and McGuire, K.:, Taking the pulse of hydrology education, Hydrol. Process., 21, 1789-1792, 2007.

Walton, G., Childs, C., and Blenkinsopp, E.: Using mobile technologies to give health students access to learning resources in the UK community setting, Health Info. Libr. J., 22 (Suppl. 2), 51-65, 2005. 